\title{
Pitch accent distribution in German infant-directed speech
}

\author{
Katharina Zahner, Muna Pohl, Bettina Braun \\ ${ }^{1}$ Department of Linguistics, University of Konstanz, Germany \\ \{katharina.zahner|muna.pohl|bettina.braun\} @uni-konstanz.de
}

\begin{abstract}
Infant-directed speech exhibits slower speech rate, higher pitch and larger f0 excursions than adult-directed speech. Apart from these phonetic properties established in many languages, little is known on the intonational phonological structure in individual languages, i.e. pitch accents and boundary tones and their frequency distribution. Here, we investigated the intonation of infant-directed speech in German. We extracted all turns from the CHILDES database directed towards infants younger than one year $(n=585)$. Two annotators labeled pitch accents and boundary tones according to the autosegmental-metrical intonation system GToBI. Additionally, the tonal movement surrounding the accentual syllable was analyzed. Main results showed a) that $45 \%$ of the words carried a pitch accent, b) that phrases ending in a low tone were most frequent, c) that $\mathrm{H}^{*}$ accents were generally more frequent than $\mathrm{L}^{*}$ accents, d) that $\mathrm{H}^{*}, \mathrm{~L}+\mathrm{H}^{*}$ and $\mathrm{L}^{*}$ are the most frequent pitch accent types in IDS, and e) that a pattern consisting of an accentual low-pitched syllable preceded by a low tone and followed by a rise or a high tone constitutes the most frequent single pattern. The analyses reveal that the IDS intonational properties lead to a speech style with many tonal alternations, particularly in the vicinity of accented syllables.
\end{abstract}

Index Terms: intonation, infant-directed speech, pitch accent types, frequency distribution, German, GToBI

\section{Introduction}

Although infant-directed speech (IDS, "motherese") has been investigated thoroughly from a phonetic and sometimes also functional point of view $([1,2])$, relatively sparse information is available as to its phonological characteristics. In this paper, we analyze the intonational phonological structure of German IDS-utterances by examining the frequency distribution of boundary tones and pitch accent types. We analyzed utterances of 8 mothers from the CHILDES data base ([3]) and of one additional mother while they talked to their young infants.

IDS differs in several aspects from adult-directed speech (ADS): IDS has been shown to consist of shorter utterances, grammatically simpler sentences and it contains special lexical items such as "cho-cho" for train in English (e.g., [4, 5]). Furthermore, conversations with young children are marked by a high degree of repetitiveness (e.g.,[6]). Phonetically, IDS is characterized by higher mean fundamental frequency (f0), higher absolute f0, larger f0 ranges, longer pauses, more use of whispering, a reduced speech rate, final syllable lengthening and more peripheral vowel qualities (e.g., [4, 7-10]), compared to ADS. Some language-specific properties of IDS have also been reported, e.g., differences in the amount of increase in f0 range ([11]) and in the kinds of pitch accent types that are used ([12]). Nevertheless, it seems that there are at least some universal properties of IDS ([1, 13, 14]). Similarly, there are differences between mothers and fathers ([4, 15]), and the infants' gender also appears to influence features of IDS ([11, 16]). However, increases in mean $\mathrm{f} 0$ and $\mathrm{f} 0$ range seem to be relatively stable characteristics of IDS.

Apart from lexical and phonetic characteristics, there is only a limited number of studies on the phonological intonational realization of IDS across languages. For instance, [12] analyzed the distribution of pitch accent types in English and Bengali IDS and ADS. Not surprisingly, their results show that the accent inventory of IDS is based on ADS phonology and does not consist of a different set of accent types. The distribution of pitch accents, however, differs across interlocutors, with a reduced set of accents in Bengali IDS as opposed to ADS and with an increased proportion of rising contours in IDS in both languages (see also [17] on American English). Apart from that, little is known about the languagespecific intonational categories and their frequency of use in IDS. [17] further reports a higher accent density and more pitch variability, at least in American English.

American English IDS and ADS are said to differ with regard to the prosodic marking of focused words ([18]). Mothers of 14-month-old infants positioned focused words most often in utterance-final position and produced them with an exaggerated pitch peak, even if the target words were mentioned for the second time and thus discourse-given. The exact form of the accent types used in this study is, however, not reported. In the current paper, we will take a closer look at the specific pitch patterns used by mothers when speaking to infants. Data were restricted to infants younger than one year, since this is the period in which prosodic characteristics of IDS style are particularly prominent $([17,19,20])$.

\section{Background}

We analyzed the intonation of the IDS utterances following the guidelines of GToBI (German Tone \& Break Indices [21]), a widely used annotation system within the autosegmentalmetrical (AM) framework. In AM-systems, pitch accents are associated with the metrically stressed syllables of an accented word, resulting in starred tonal targets (indicated by ' $*$ '). GToBI distinguishes six different basic pitch accent types, two monotonal accents $\left(\mathrm{H}^{*}\right.$ and $\mathrm{L}^{*}$, in which the stressed syllable is perceived as high and low, respectively) and four bitonal accents, containing either leading tones or trailing tones (tones preceding or following the accentual tone). These include two rising accents that differ in the perception of the stressed syllable as high or low $\left(\mathrm{L}+\mathrm{H}^{*}\right.$ is perceived as high and $\mathrm{L}^{*}+\mathrm{H}$ 
as low) and two early falls $\left(\mathrm{H}+\mathrm{L}^{*}\right.$ with a prominent pitch fall onto the stressed syllable (high to low) and $\mathrm{H}+$ ! $\mathrm{H}^{*}$ where the fall is less steep (high to mid-level)).

Two levels of phrasing are annotated: intermediate phrases (ips, indicated by '-') and superordinate intonational phrases (IPs, '\%'). Due to the prosodic hierarchy, an IP-boundary always subsumes an ip-boundary. GToBI's IP boundary tone inventory at the right edges of an IP consists of five different types: $\mathrm{H}-\%$ (high plateau), $\mathrm{H}-\wedge \mathrm{H} \%$ (high-rise), L-H\% (lowrise), L-\% (fall/low, depending on the preceding pitch accent), !H-\% (incomplete fall). The default initial boundary tone is $\% \mathrm{~L}$; an extraordinarily high beginning is marked by $\% \mathrm{H}$. Each $\mathrm{H}$-tone can be realized higher or lower than a preceding $\mathrm{H}$ tone in the same IP, indicated by upstep $\left(^{\wedge}\right)$ and downstep (!).

\section{Methods}

\subsection{Data selection}

We selected all German utterances to children younger than one year (ranging from $0 ; 5.4$ to $0 ; 11.23$ ) from the CHILDES database ([3]). These included four mothers from the Stuttgart Corpus ([22]) and four mothers from the Manuela Corpus ("http://childes.psy.cmu.edu/browser/index.php?url=Germanic /German/Manuela/01dasca1.cha"). All infants ( 7 boys and 1 girl) came from monolingual German-speaking homes and were recorded at home while their parents interacted with them, resulting in typical playing situations involving picture books, toys and other objects.

We extracted all infant-directed units uttered by female speakers ( $\mathrm{n}=932$ turns). Of these, 89 had to be excluded from the analysis due to bad quality, such as overlapping speech, crying, noise or laughter. We further excluded interjections $(\mathrm{n}=145)$, non-referential onomatopoeia $(\mathrm{n}=46)$, and short IPs that were incomprehensible ( $\mathrm{n}=67)$. In sum, 585 turns $(18 \mathrm{~min}$ $40 \mathrm{sec}$ of speech, 2270 words, 673 IPs) from 8 different mothers were intonationally analyzed. On average, an IP contained 3.4 words, ranging from 1 to 15 words. An IP contained 1.5 pitch accents on average. $45 \%$ of the words carried a pitch accent (1016 out of 2270). Note that $78 \%$ of the data (456 turns) came from one mother, which might skew the results. In order to better generalize from the data, we created a more balanced dataset that contained only 50 of her turns (randomly selected). This is the same number of turns as of the mother of whom we had the second-most turns. We compensated for some of the excluded data by adding 21 turns from another mother-child interaction from a private video. This infant is 5 months of age and both parents are native speakers of German. In what follows, we present the results from the full and the balanced data set in parallel.

\subsection{Data Analysis}

The utterances were first annotated on the lexical word level. Next, two annotators trained in GToBI labeled the corpus together. They first identified the phrasing (IPs/ips), then the accented syllables and the respective accent types. Annotators paid particular attention to the distinction between $\mathrm{L}^{*}+\mathrm{H}$ and $\mathrm{L}+\mathrm{H}^{*}$, which is often confused (e.g., [23, 24]); they assigned these two accent types based on the perceptual impression of the accented syllable as low $\left(\mathrm{L}^{*}+\mathrm{H}\right)$ or high $\left(\mathrm{L}+\mathrm{H}^{*}\right)$ Disagreements were discussed and resolved. The most frequent disagreement involved the annotation of $\mathrm{H}^{*} / \mathrm{H}^{*} / \mathrm{L}^{*}$ $(11 \%)$ by one annotator and no accent by the other. In case of disagreement, these cases were labeled as accents. A further frequent disagreement arose for $\mathrm{L}+\mathrm{H}^{*}$ vs. $\mathrm{H}^{*}$ and $\mathrm{L}-\mathrm{H} \%$ vs. $\mathrm{H}-{ }^{\wedge} \mathrm{H} \%$ ( $8 \%$ and $7.5 \%$ disagreement, respectively), both involving differences in scaling. These disagreements were resolved by comparing the respective accent to more prototypical realizations of the same speaker.

We deviated from the standard GToBI guidelines in two aspects, both regarding boundaries: First, when there was an $\mathrm{H}$-tone on the first syllable of the word $\left(\mathrm{H}^{*}, \mathrm{H}+\mathrm{L}^{*}, \mathrm{H}+\mathrm{H}^{*}\right)$, the initial boundary was also marked as $\% \mathrm{H}$ as this corresponds to the actual acoustic realization, while the phonologically motivated choice of the $\% \mathrm{~L}$ as default would have not been faithful to the actual intonation contour. Second, before a final rise ( $\left.\mathrm{L}-\mathrm{H} \%, \mathrm{H}^{-} \mathrm{H} \%\right)$ and a high plateau $(\mathrm{H}-\%)$, a low-pitched accented syllable was always marked as $\mathrm{L}^{*}$, i.e., no distinction was made between $\mathrm{L}^{*}$ and $\mathrm{L}^{*}+\mathrm{H}$. Due to the use of simple words in IDS, there were not enough syllables after the accentual tone to reliably differentiate between $\mathrm{L}^{*}$ and $\mathrm{L}^{*}+\mathrm{H}$ accents in this context. Note that these conventions may slightly overestimate the counts for $\% \mathrm{H}$ and $\mathrm{L}^{*}$.

In a second step, we analyzed the tonal movement to and from the accentual syllable (conceptually following PaIntE ([25]), a method that has also been used for the analysis of infant-directed speech, ([26])). In contrast to PaIntE, which is based on acoustic analysis of the f0 contour, we classified the tonal targets surrounding the accentual tones perceptually as high or low (often, the poor quality of the recordings would not have made an automated acoustic analysis possible). For instance, an $\mathrm{L}^{*}$ accent that was preceded by low pitch and followed by high pitch was classified as the tritonal pattern "LL*H". This tritonal analysis accounts for the fact that GToBI describes leading tones in some pitch accents $\left(\mathrm{L}+\mathrm{H}^{*}\right.$, $\left.\mathrm{H}+\mathrm{H}^{*}, \mathrm{H}+\mathrm{L}^{*}\right)$ and trailing tones in others $\left(\mathrm{L}^{*}+\mathrm{H}\right)$, but never both at the same time. Note that the inventory of pitch accent types (and hence the decision to describe leading or trailing tones for particular accents) is based on phonological theory and adults' perception (see [27] for the perceptual relevance of leading tones). Other German transcription systems use different inventories (e.g., [28] or [29]). Since we do not know what infants are sensitive to, our tritonal analysis does not take the phonological status of surrounding tones into account (be they GToBI trailing tones or phrase accents) but only classifies the f0 level of surrounding targets. The following criteria were used: First, the tonal targets preceding and following the accentual tone were always specified, irrespective of the distance of a preceding or following tonal target. The classification does hence not give information on the slope of the movement to and from the accentual tone (unlike PaIntE). Second, if there were no preceding or following syllables, the accentual tone was copied if there was no movement and specified with the opposite tone if there was a tonal movement (e.g., "HH*L" for a monosyllabic fall). Figure 1 shows a case in which a phrase-initial $\mathrm{L}^{*}+\mathrm{H}$ accent is categorized as "LL* $\mathrm{H}$ " even though there is no additional low-toned syllable that precedes the accented syllable. Figure 2 shows a case in which the tone following the accentual one is not realized on the immediately following syllable but later in the phrase, leading to a shallow fall.

In order to keep the number of patterns manageable, we ignored differences resulting from the scaling of a tritonal pattern. For instance, an $\mathrm{H}+! \mathrm{H}^{*} \mathrm{H}-\%$ (early fall ending in a 
high plateau) was counted as "HL* $\mathrm{L}$ " (see second accent in Figure 1 and last accent in Figure 3). Note that the distribution of patterns hardly changes when only the "core" patterns are counted (i.e. when tonally similar patterns in a higher pitch register are not taken into account). For the sake of clarity, these numbers are omitted in the current paper: our classification hence focuses on the local tonal movement around the accented syllable and ignores scaling differences that are induced by preceding tonal events (upstep and downstep). Note that we do not propose to add tritonal pitch accents for the intonational description of German IDS but provide an analysis that focuses on the tonal movements around the accentual syllable.

Figure 1: Contour with a hat pattern followed by an incomplete fall (smoothed fo shown between 200 and $400 \mathrm{~Hz}$ );

the accented syllables are shown on the third tier, GToBI notation on the fourth and the tritonal analysis on the fifth tier.

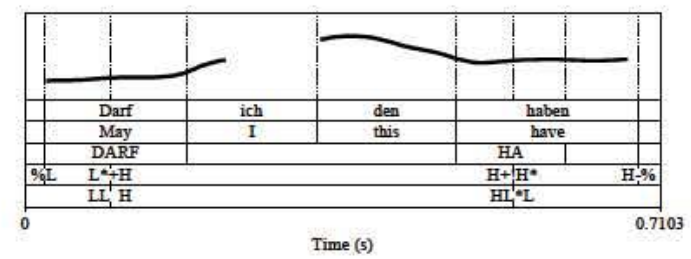

Figure 2: Contour with two rising accents followed by a high plateau (fo between 100 and $500 \mathrm{~Hz}$ ).

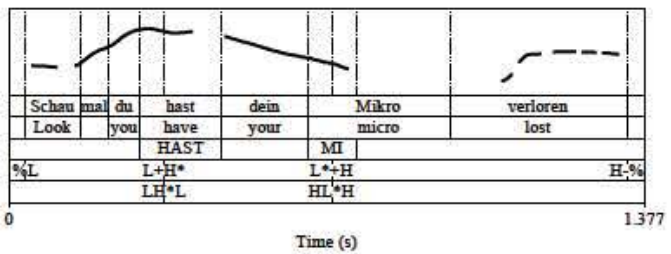

Figure 3: Contour with five pitch accents ending in a high rise (fo between 100 and $500 \mathrm{~Hz}$ ).

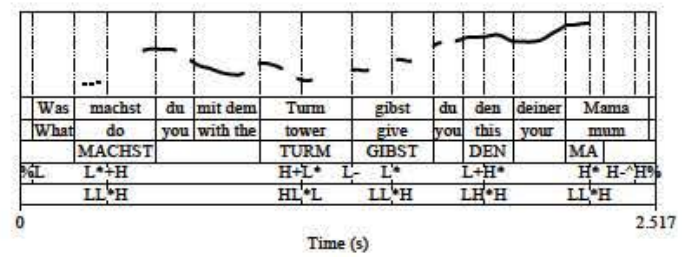

\section{Results and Discussion}

Table 1 shows the distribution of boundary tones, Table 2 the distribution of the most frequent pitch accent types. Note that the percentages are similar for the full and the balanced data set. Even when there are numeric differences, the frequency ranking does not change across sets.

Initial boundary tones. In the majority of cases, the utterances started with a low boundary tone $(65 \%)$. The annotators further identified some cases in which the boundary was neither strictly $\% \mathrm{~L}$ nor $\% \mathrm{H}$; these 23 cases $(3 \%)$ only occurred before accents starting with a low tonal target $\left(\mathrm{L}^{*}+\mathrm{H}\right.$,
$\mathrm{L}+\mathrm{H}^{*}$ or $\left.\mathrm{L}^{*}\right)$. For the current analysis, these intermediate cases were preliminarily grouped as $\% \mathrm{~L}$; future research is necessary to determine whether a $\% \mathrm{M}$ category may be useful for the transcription of IDS.

Final boundary tones. The most frequent boundary tone was L- $\%(46 \%$ of the IPs). The next frequent patterns were a high plateau $(\mathrm{H}-\%)$ and a low rise ( $\mathrm{L}-\mathrm{H} \%)$. Incomplete falls $(! \mathrm{H}-\%)$ and high rises $\left(\mathrm{H}-{ }^{\wedge} \mathrm{H} \%\right)$ were least frequent. The two plateaupatterns (H-\%, !H-\%) were usually accompanied by significant segmental lengthening (see also $[29,30]$ ). Since the situations in the corpus involved a variety of interactions (teaching words, seeking the infants' attention, describing pictures, playing, instructing), the range of boundary tones we see here may be representative of the infants' input. An analysis of the pragmatic, functional aspects of the boundary tones are beyond the scope of this paper, but are surely important to further our understanding of the form-function mapping in IDS (and potential differences to ADS).

Table 1. Distribution of boundary tones.

\begin{tabular}{|c|c|c|c|}
\hline Label & Contour & $\begin{array}{c}\text { All data } \\
(673 \mathrm{IPs})\end{array}$ & $\begin{array}{c}\text { Balanced set } \\
(214 \mathrm{IPs})\end{array}$ \\
\hline$\% \mathrm{~L}$ & Low onset & $68 \%$ & $65 \%$ \\
$\% \mathrm{H}$ & High onset & $31 \%$ & $35 \%$ \\
\hline $\mathrm{L}-\%$ & Fall/Low & $46 \%$ & $44 \%$ \\
\hline $\mathrm{H}-\%$ & High plateau & $23 \%$ & $19 \%$ \\
!H- $\%$ & Incomplete fall & $11 \%$ & $10 \%$ \\
\hline L-H\% & Low rise & $13 \%$ & $17 \%$ \\
$\mathrm{H}-\mathrm{H}^{2} \%$ & High rise & $6 \%$ & $9 \%$ \\
\hline
\end{tabular}

Pitch accent types. The most frequent accent types were $\mathrm{H}^{*} / ! \mathrm{H}^{*}, \mathrm{~L}^{*}$ and $\mathrm{L}+\mathrm{H}^{*}$, all accounting for more than $20 \%$ of the accents. The high proportion of $\mathrm{H}^{*}$ and $\mathrm{L}+\mathrm{H}^{*}$ accents is expected as they constitute the default accents for new and contrastive referents in German ([31]). On the other hand, the high proportion of $\mathrm{L}^{*}$ accents may be partly explained by our labeling convention (default for low-toned accentual tones preceding a high boundary). Indeed, as shown in the tritonal analysis below, $\mathrm{L}^{*}$ was often followed by a high tone, such as a high boundary tone (Table 3 ). The next frequent accent was $\mathrm{L}^{*}+\mathrm{H}$, accounting for $15 \%$ of the CHILDES data (and $10 \%$ in the balanced data set). These $\mathrm{L}^{*}+\mathrm{H}$ accents often occurred in a so-called hat pattern, i.e., as prenuclear accents that were followed by an $\mathrm{H}+\mathrm{L}^{*}$ or $\mathrm{H}+! \mathrm{H}^{*}$ accent (see [32], and Figure 1) and have been reported to be frequent in southern German varieties (e.g., [33, 34]). Least frequent were accents with an early peak $\left(\mathrm{H}+\mathrm{L}^{*}, \mathrm{H}+\mathrm{H}^{*}\right)$, which are assumed to signal given/accessible referents in German (e.g., [35]). Although mothers often repeated referents, so that subsequent mentions were discourse-given, mothers did not consistently avoid $\mathrm{H}^{*}$ and $\mathrm{L}+\mathrm{H}^{*}$ accents in these contexts, in line with [18].

Table 2. Distribution of frequent pitch accent types.

\begin{tabular}{|c|c|c|}
\hline Label & $\begin{array}{c}\text { All data } \\
(1016 \text { accents })\end{array}$ & $\begin{array}{c}\text { Balanced set } \\
(341 \text { accents })\end{array}$ \\
\hline $\mathrm{H}^{*} ! \mathrm{H}^{*}$ & $29 \%$ & $35 \%$ \\
\hline $\mathrm{L}+\mathrm{H}^{*}$ & $21 \%$ & $21 \%$ \\
\hline $\mathrm{L}^{*}+\mathrm{H}$ & $15 \%$ & $10 \%$ \\
\hline $\mathrm{L}^{*}$ & $22 \%$ & $24 \%$ \\
\hline $\mathrm{H}^{+} \mathrm{L}^{*}$ & $8 \%$ & $7 \%$ \\
\hline $\mathrm{H}+! \mathrm{H}^{*}$ & $4 \%$ & $3 \%$ \\
\hline
\end{tabular}


Tritonal analyses. Table 3 shows the $\mathrm{f} 0$ movement around the accentual tone. Interestingly, the strongest tonal contrast around the accentual tone ("HL* $\mathrm{H}$ ", " $\mathrm{LH} \mathrm{H}^{*} \mathrm{~L}$ "), which supposedly makes the accentual syllable tonally extra salient, was not equally frequent for low and high accentual tones. Instead, the "peak pattern" ("LH* $\mathrm{L}$ ") was more than twice as frequent as the "dip pattern" ("HL* $\mathrm{H}$ ").

Table 3. Distribution of fo movement around the accentual tone (*). T refers to either $H$ or L tone.

\begin{tabular}{|c|c|c|}
\hline $\begin{array}{c}\text { F0-movement around } \\
\text { accentual tone }\end{array}$ & $\begin{array}{c}\text { All data } \\
(1016 \text { accents })\end{array}$ & $\begin{array}{c}\text { Balanced set } \\
(341 \text { accents })\end{array}$ \\
\hline "LH*L" & $18 \%$ & $18 \%$ \\
\hline "HH*L" & $14 \%$ & $17 \%$ \\
\hline "LH*H" & $8 \%$ & $9 \%$ \\
\hline "HL*L" & $12 \%$ & $12 \%$ \\
\hline "HL*H" & $8 \%$ & $6 \%$ \\
\hline "LL*H" & $25 \%$ & $24 \%$ \\
\hline \\
\hline
\end{tabular}

A further asymmetry involves patterns in which only one of the surrounding tones changes. In these cases, a change to the right (rows 2 and 6) seems to be preferred over a change from the left (rows 3 and 4). Future research will have to determine whether this asymmetry is inherent in the distribution of pitch accents or is rather caused by the differential influence of initial and final boundary tones. By far the most frequent single accentual pattern was " $L L * H$ ", i.e., a low accentual tone followed by a high tone. This high tone was often, but not always a phrase accent (H-) or boundary tone (L-H\%).

Monotonous patterns (" $L \mathrm{~L} * \mathrm{~L}$ " and " $\mathrm{HH} * \mathrm{H}$ ") were very rare, possibly because they stand out merely by metrical prominence and not by tonal movement. A recent proposal for intonational annotation in German argues for a separation of metrical prominence (signaled mainly by duration and intensity) and tonal characteristics ([36]). Had we used this separation, we would not have tonally annotated some of these $\mathrm{H}^{*}$ and $\mathrm{L}^{*}$ accents at all. Staircase patterns (last two rows) were equally rare.

Finally, we would like to note that not all IPs were produced with a large, expanded pitch range as suggested from the literature. Furthermore, we also observed cases in which more accents were placed on a single word. This mainly involved compounds and particle verbs (see also [17] for American English compounds). For instance, the compound "Sandeleimer" ['zan.dəl.,?aI,me] (toy bucket) received an additional pitch accent on the syllables that carry secondary stress. We occasionally also found accents on unstressed syllables, such as the second syllable in "prima" ['pri:.ma] (perfect), as displayed in Figure 4.
Figure 4: Contour of the word "prima" with two pitch accents within one word (100 and $500 \mathrm{~Hz}$ ).

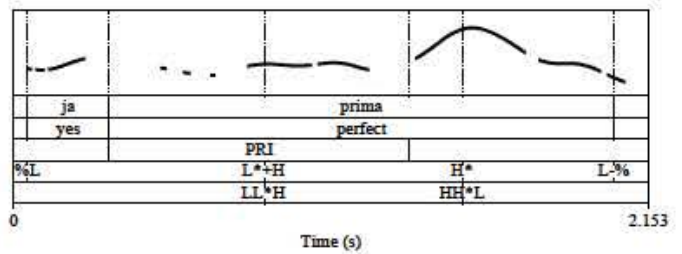

\section{Conclusion and outlook}

We presented an intonational analysis of IDS in German, directed to prelinguistic infants. Utterances were analyzed using GToBI, a phonological annotation system within the AM tradition. Furthermore, the accents were classified according to accentual tones and tonal movements in surrounding syllables, leading to tritonal patterns with the accentual tone in the middle (a more categorical equivalent to PaIntE). $45 \%$ of the words carried a pitch accent; sometimes a single word even received more than one accent, leading to considerable tonal variability. Phonologically, the majority of utterances started with a low boundary tone $(65 \%)$. At the right edge, low-ending utterances ( $\mathrm{L}-\%)$ were the most frequent category, but they did not constitute the majority (occurring in only $46 \%$ of the utterances). The majority of utterances hence ended in some sort of high tone. Of these high-ending phrases, the high plateau $(\mathrm{H}-\%)$ occurred most often, followed in frequency by the low-rise ( $\mathrm{L}-\mathrm{H} \%)$; the incomplete fall $(! \mathrm{H}-\%)$ and the high rise $\left(\mathrm{H}-{ }^{\wedge} \mathrm{H} \%\right)$ were least frequent. Regarding the choice of pitch accents, four types were particularly frequent $\left(\mathrm{H}^{*} / ! \mathrm{H}^{*}, \mathrm{~L}^{*}, \mathrm{~L}+\mathrm{H}^{*}, \mathrm{~L}^{*}+\mathrm{H}\right.$, in order of descending frequency). Accent types with an early peak $\left(\mathrm{H}+\mathrm{L}^{*}, \mathrm{H}+\mathrm{H}^{*}\right)$ were very rare. The tritonal analysis showed that monotonous and staircase patterns are only sparsely represented in the data. $\mathrm{H}^{*}$ accentual tones (with a low tone before or after them) were more frequent than $\mathrm{L}^{*}$ accentual tones (with surrounding $\mathrm{H}$ tones). The " $\mathrm{LL} * \mathrm{H}$ " pattern stands out as the single most frequent pattern, possibly due to its use in polar questions ([37]) (which frequently occur in the infants' input ([18])) and due to regional influence ([33, 34]). Unfortunately, we do not have data to directly compare the distribution to ADS utterances from the same speakers. Existing analyses focused on northern German varieties ([38]) and on read speech ([39]), which is not directly comparable. We will have to leave this comparison to future research.

We are currently collecting more audio files to enrich the dataset and to investigate whether the high proportion of $\mathrm{L}^{*}+\mathrm{H}$ accents is indeed a regional southern phenomenon $([33,34])$ or whether this accent type is a peculiar phonological feature of IDS. Furthermore, we are analyzing the form-function mapping, in particular with regard to the meaning of boundary tones and the marking of referential givenness by caregivers.

\section{Acknowledgements}

We are very grateful to Isabelle Auriga for help with preparation and analyses of the data. We further appreciate discussion of data at the DIMA meeting in Potsdam (March 2015). We particularly thank Janet Grijzenhout, the head of the Baby Speech Lab of the University of Konstanz, for cooperating in enriching the current dataset. 


\section{References}

[1] M. Papoušek, H. Papoušek, and D. Symmes, "The meanings of melodies in motherese in tone and stress languages," Infant Behavior and Development, vol. 14, pp. 415-440, 1991.

[2] D. N. Stern, S. Spieker, and K. MacKain, "Intonation contours as signals in maternal speech to prelinguistic infants," Developmental Psychology, vol. 18, pp. 727-735, 1982.

[3] B. MacWhinney, The CHILDES project tools for analyzing talk., 3rd ed. vol. 2: The Database. Mahwah, NJ: Lawrence Erlbaum Associates, 2000

[4] A. Fernald, T. Taeschner, J. Dunn, M. Papoušek, B. de BoyssonBardies, and I. Fukui, "A cross-language study of prosodic modifications in mothers' and fathers' speech to preverbal infants," Journal of Child Language, vol. 16, pp. 477-501, 1989.

[5] C. A. Ferguson, "Baby talk in six languages," American Anthropologist, vol. 66, pp. 103-114, 1964.

[6] L. J. Ferrier, "Some observations of error in context.," in The development of communication, N. Waterson and C. Snow, Eds., New York: Wiley, 1978, pp. 301-309.

[7] A. Fernald and T. Simon, "Expanded intonation contours in mothers' speech to newborns," Developmental Psychology, vol. 20, pp. 104-113, 1984

[8] B. Shute and K. Wheldall, "Pitch alterations in British motherese: Some preliminary acoustic data," Journal of Child Language, vol. 16, pp. 503-512, 1989.

[9] H. M. Liu, P. K. Kuhl, and F.-M. Tsao, "An association between mother's speech clarity and infants' speech discrimination skills," Developmental Science, vol. 6, pp. F1-F10, 2003.

[10] D. Burnham, C. Kitamura, and U. Vollmer-Conna, "What's new, pussycat? On talking to babies and animals," Science, vol. 296, p. 1435,2002

[11] C. Kitamura, C. Thanavishuth, D. Burnham, and S. Luksaneeyanawin, "Universality and specificity in infantdirected speech: Pitch modifications as a function of infant age and sex in a tonal and non-tonal language," Infant Behavior and Development, vol. 24, pp. 372-392, 2002.

[12] K. M. Yu, S. ud Dowla Khan, and M. Sundara, "Intonational phonology in Bengali and English infant-directed speech," in Speech Prosody, Dublin, Ireland, 2014, pp. 1130-1133.

[13] D. L. Grieser and P. K. Kuhl, "Maternal speech to infants in a tonal language: Support for universal prosodic features in motherese," Developmental Psychology, vol. 24, pp. 14-20, 1988.

[14] J. F. Werker, J. E. Pegg, and P. J. McLeod, "A cross-language investgation of infant preference for infant-directed communication," Infant Behavior and Development, vol. 17, pp. 323-333, 1994

[15] A. Warren-Leubecker and J. N. Bohannon III, "Intonation patterns in child-directed speech: Mother-father differences," Child Development, vol. 55, pp. 1379-1385, 1984.

[16] T. L. Weppelmann, A. Bostow, R. Schiffer, E. Elbert-Perez, and R. S. Newman, "Children's use of the prosodic characteristics of infant-directed speech," Language \& Communication, vol. 23 pp. 63-80, 2003

[17] O. K. Garnica, "Some Prosodic and Paralinguistic Features of Speech to Young Children," in Talking to children Language input and acquisition, C. E. Snow and C. A. Ferguson, Eds., Cambridge, MA: Cambridge University Press, 1977, pp. 63-88.

[18] A. Fernald and C. Mazzie, "Prosody and focus in speech to infants and adults," Developmental Psychology, vol. 27, pp. 209$221,1991$.

[19] D. N. Stern, S. Spieker, R. K. Barnett, and K. MacKain, "The prosody of maternal speech: Infant age and context related changes," Journal of Child Language, vol. 10, pp. 1-15, 1983.

[20] S. Vosoughi and D. Roy, "A longitudinal study of prosodic exaggeration in child-directed speech," in Speech Prosody, Speech Prosody Special Interest Group (SProSIG), 2012.

[21] M. Grice and S. Baumann, "Deutsche Intonation und GToBI," Linguistische Berichte, vol. 191, 2002.

[22] B. Lintfert and B. Möbius, "PhonBank German Stuttgart Corpus," Stuttgart: TalkBank, 2009.
[23] B. Braun, "Phonetics and phonology of thematic contrast in German," Language and Speech, vol. 49, pp. 451-493, 2006.

[24] M. Grice, M. Reyelt, R. Benzmüller, J. Mayer, and A. Batliner, "Consistency in transcription and labelling of German intonation with GToBI," in 4th International Conference on Spoken Language Processing (ICSLP), Philadelphia, U.S.A., 1996, pp. 1716-1719.

[25] G. Möhler and A. Conkie, "Parametric modelling of intonation using vector quantization," in 3rd ESCA Workshop on Speech Synthesis, 1998, pp. 311-316.

[26] B. Lintfert, A. Schweitzer, and B. Möbius, "A parametric approach to intonation acquisition research: Validation on childdirected speech data," in Interspeech, 2011, pp. 757-760.

[27] S. Ritter and M. Grice, "The role of tonal onglides in German nuclear pitch accents," Language and Speech, vol. Mar 58(Pt 1), pp. 114-128, 2015

[28] J. Peters, Intonation. Heidelberg: Winter, 2014.

[29] J. Mayer, "Transcription of German intonation - the Stuttgart system," University of Stuttgart, Tech. Rep. 1995.

[30] J. Peters, "Tonal effects on rhythm in west middle German," in Speech Prosody, Aix-en-Provence, 2002, pp. 567-570.

[31] K. Kohler, "Terminal intonation patterns in single-accent utterances of German: phonetics, phonology and semantics," Arbeitsberichte des Instituts für Phonetik und digitale Sprachverarbeitung der Universität Kiel (AIPUK), vol. 25, pp. 115-185, 1991.

[32] H. Truckenbrodt, "Upstep on edge tones and on nuclear accents," in Tones and tunes. Volume 2 Experimental studies in word and sentence prosody, C. Gussenhoven and T. Riad, Eds., Berlin: Mouton de Gruyter, 2007.

[33] F. Kügler, The intonational phonology of Swabian and Upper Saxon. Tübingen: Niemeyer, 2007.

[34] M. Atterer and D. R. Ladd, "On the phonetics and phonology of "segmental anchoring" of F0: Evidence from German," Journal of Phonetics, vol. 32, pp. 177-197, 2004.

[35] S. Baumann and M. Grice, "The intonation of accessibility," Journal of Pragmatics, vol. 38, pp. 1636-1657, 2006.

[36] F. Kügler, B. Smolibocki, D. Arnold, S. Baumann, B. Braun, M. Grice, S. Jannedy, J. Michalsky, O. Niebuhr, J. Peters, S. Ritter, C.T. Röhr, A. Schweitzer, K. Schweitzer, and P. Wagner, "DIMA - Annotation guidelines for German intonation," in International Congress on Phonetic Science, Glasgow, Scotland, 2015.

[37] M. Grice, S. Baumann, and R. Benzmüller, "German intonation in autosegmental-metrical phonology," in Prosodic Typology. The Phonology of Intonation and Phrasing, J. Sun-Ah, Ed., ed Oxford: Oxford University Press, 2005, pp. 55-83.

[38] B. Peters, K. Kohler, and T. Wesener, "Melodische Satzakzentmuster in prosodischen Phrasen deutscher Spontansprache - Statistische Verteilung und sprachliche Funktion [Melodic sentence accent patterns in spontaneous German prosodic phrases - statistical distribution and linguistic function]" in Prosodic Structures in German Spontaneous Speech (AIPUK 35a), K. Kohler, F. Kleber, and B. Peters, Eds., Kiel: IPDS, 2005, pp. 185-201.

[39] H. Truckenbrodt, "Upstep and embedded register levels," Phonology, vol. 19, pp. 77-120, 2002. 